\title{
Inter-oceanic analysis of demographic variation in a widely distributed Indo-Pacific coral reef fish
}

\author{
Elizabeth L. Trip ${ }^{1,4}$, J. Howard Choat ${ }^{1, *}$, David T. Wilson ${ }^{2,5}$, D. Ross Robertson ${ }^{3}$ \\ ${ }^{1}$ School of Marine and Tropical Biology, James Cook University, Townsville, Queensland 4811, Australia \\ ${ }^{2}$ Department of Marine and Wildlife Resources, Pago Pago, AS 96799, American Samoa \\ ${ }^{3}$ Smithsonian Tropical Research Institute, Unit 0948, Apartado 2072, Balboa, Panama \\ ${ }^{4}$ Present address: Ecology and Evolution, School of Biological Sciences, University of Auckland, Private Bag 92019, \\ Auckland, New Zealand \\ ${ }^{5}$ Present address: Bureau of Rural Sciences, Fisheries and Marine Science Program, GPO Box 858, \\ Canberra, ACT 2601, Australia
}

\begin{abstract}
The surgeonfish Ctenochaetus striatus is abundant and widely distributed on reefs throughout the Indian and Pacific Oceans. Population samples at 15 sites that spanned $158^{\circ}$ of longitude and $40^{\circ}$ of latitude across both hemispheres of the Indian and Pacific oceans allowed us to examine geographic variation in longevity, growth rate and adult size of this species. Samples from 5 sites in the Indian Ocean, 6 in the western Pacific and 4 in the central Pacific provided otolith-based estimates of size-at-age for 1537 individuals. All populations displayed rapid growth to a distinct asymptotic size, a pattern characteristic of many acanthuroid fishes. In both oceans, fish lived longer at higher latitudes; in addition, Indian Ocean populations tended to be shorter-lived than those in the Pacific Ocean. In contrast, growth rate and adult size did not differ between the 2 oceans, and were not related to temperature (as a proxy for latitude) in either the Pacific or the Indian Ocean. Further, we found no relationship between fishing pressure and longevity, growth or adult size across our set of sampling sites, among which fishing pressure on this species varied from intense to zero. We hypothesize that (1) growth and adult size are most responsive to local environmental features unrelated to latitudinal (temperature) effects; and (2) variation in longevity reflects a combination of responses to latitudinal (temperature) gradients and as yet unidentified environmental differences between the Indian and Pacific oceans.
\end{abstract}

KEY WORDS: Longitudinal and latitudinal gradients · Longevity · Body size · Growth rate Asymptotic growth · Coral reef fish · Acanthuridae

Resale or republication not permitted without written consent of the publisher

\section{INTRODUCTION}

Coral reef fishes display substantial demographic variation over their distributional ranges. This is most obvious in body size, growth rates and age structure. Demographic variation occurs at a number of scales ranging from different habitats of the same reef system (Choat \& Axe 1996, Gust et al. 2002, Robertson et al. 2005a), to geographic trends manifested over thousands of kilometers (Robertson et al. 2005a). Establishing the causes of demographic variation is a challeng- ing task, as 4 sources of variation will all play a part: the physical environment, biological assemblages, evolutionary histories of reef habitats and human impacts. Sampling over latitudinal gradients, where trends in temperature are associated with predictable patterns of demographic variation in many organisms, is a useful starting point.

Increasing body size with latitude has been recorded for both temperate (Yamahira \& Conover 2002) and tropical fish species (Meekan et al. 2001, Choat et al. 2003, Robertson et al. 2005a, Ruttenberg et al. 2005). 
This conforms to a general relationship between body size and temperature in ectotherms (Ashton \& Feldman 2003, Kingsolver \& Huey 2008). Somatic growth rates may also be sensitive to differences in temperature. An example is provided by counter-gradient growth patterns in which individuals at higher latitudes grow faster than those at lower latitudes (Conover 1990, Conover \& Present 1990). However, there are still relatively few examples of examinations of systematic trends in body size and growth rates in tropical fishes, even though their distributions make them ideal subjects for such studies.

In a comprehensive analysis of demographic variation in the Caribbean coral reef fish Acanthurus bahianus, Robertson et al. (2005a) identified 3 major demographic trends over a latitudinal gradient of $5500 \mathrm{~km}$. Size, growth rate and longevity all displayed a positive relationship with latitude (temperature), with the strongest effect seen on the distribution of maximum life spans. However, these authors also identified pronounced local scale (habitat) variation in size and growth of $A$. bahianus, and concluded that this was a pervasive aspect of reef fish demography that required standardized sampling of habitats in comparative analyses. The configuration of reef systems within the tropical Atlantic allowed sampling of A. bahianus within a relatively narrow longitudinal range, and permitted demographic analyses without the confounding effects of divergent reef and ocean histories that may be associated with inter-ocean comparisons.

In contrast to those in the Atlantic, Indo-Pacific reefs extend over a longitudinal range of $20000 \mathrm{~km}$ and 2 ocean basins. Although latitudinal gradients of similar magnitude to that in the Acanthurus bahianus study can be accessed in the Indo-Pacific, sampling must also incorporate the longitudinal component of species distribution. Sampling Indo-Pacific taxa at large geographic scales raises 2 problems. While latitudinal sampling across systematic gradients in temperature allows interpretation of demographic trends in the context of a well established body of observational and experimental data (Kingsolver \& Huey 2008), longitudinal sampling can incorporate different ocean basins with distinct evolutionary histories, regional oceanographic environments and geographical patterns of reef distribution. How this will impact on demographic variables is presently unclear. In addition, different patterns of reef distribution in each ocean basin make it difficult to achieve balanced geographic sampling with respect to latitudinal and longitudinal sources of variation. Consequently, the sampling program for the present study was exploratory, and designed to facilitate the development of more informative hypotheses concerning broad-scale demographic variation in Indo-Pacific reef fishes.
The present study evaluates patterns of demographic variation in a widely distributed Indo-Pacific reef fish over significant latitudinal and longitudinal gradients. The target species, the surgeonfish Ctenochaetus striatus (Quoy and Gaimard), has a wide distribution extending across $\sim 190^{\circ}$ of longitude from the Red Sea and the eastern coast of Africa $\left(\sim 29^{\circ} \mathrm{E}\right)$ to the central Pacific region $\left(\sim 140^{\circ} \mathrm{W}\right)$, and across $60^{\circ}$ of latitude from $26^{\circ} \mathrm{N}$ to $34^{\circ} \mathrm{S}$ (Randall \& Clements 2001). A number of demographic variables can be extracted from sectioned sagittal otoliths of this species, for which the annular nature of growth-increment formation has been validated (Choat \& Axe 1996). Preliminary information indicates variation in size structure and maximum ages among localities in this species (Choat \& Axe 1996, Choat \& Robertson 2002).

We examined demographic traits (size, growth rate and longevity) of this species over a gradient spanning $20^{\circ}$ of latitude across both oceans, to determine (1) the nature of the relationship between temperature, somatic size and growth rates; and (2) whether there was a positive relationship between latitude and life span, as is seen in tropical Atlantic Acanthurus. In addition, we sampled across $158^{\circ}$ of longitude $(17360 \mathrm{~km})$ in both the Indian and Pacific oceans to explore the magnitude and pattern of demographic variation within a species whose range spans much of both ocean basins that constitute the Indo-Pacific reef system.

\section{MATERIALS AND METHODS}

Data collection. Samples were collected in the western, northern and central Indian Ocean, and the western and central South Pacific Ocean. At all but one site, sampling was standardized by habitat with fish collected from the crests and outer slopes of reefs. The exception was Samoa, where all samples were collected in back reef habitats. In the Indian Ocean, fish were sampled on the reefs fringing the granitic northern islands of the Seychelles $\left(55^{\circ} 4^{\prime} \mathrm{E}, 4^{\circ} 3^{\prime} \mathrm{S}\right)$, the coral reefs of the Amirantes Island group $\left(53^{\circ} 1^{\prime} \mathrm{E}, 6^{\circ} \mathrm{S}\right.$, 230 to $1150 \mathrm{~km}$ southwest of the Seychelles), the $\mathrm{Al}$ Halaaniyaat Islands off the south coast of Oman $\left(56^{\circ} \mathrm{E}\right.$, $17^{\circ} 3^{\prime} \mathrm{N}$ ), which are in a productive upwelling region supporting a mixture of rocky, algal and coral reefs, and at the Cocos Keeling Islands $\left(96^{\circ} 5^{\prime} \mathrm{E}, 12^{\circ} 3^{\prime} \mathrm{S}\right)$ in the eastern Indian Ocean. At Cocos Keeling, independent samples were collected in 2 habitats: (1) the lagoon and (2) the reef crest. In the western South Pacific Ocean, samples were collected from Papua New Guinea (PNG) in Kavieng $\left(152^{\circ} 5^{\prime} \mathrm{E}, 3^{\circ} 7^{\prime} \mathrm{S}\right)$ and in Kimbe Bay $\left(151^{\circ} \mathrm{E}, 5^{\circ} \mathrm{S}\right)$, and along the Great Barrier Reef, Australia (GBR) from Lizard Island at the northern end of the GBR $\left(145^{\circ} 3^{\prime} \mathrm{E}, 14^{\circ} 4^{\prime} \mathrm{S}\right)$, from the mid- 
shelf reefs off Townsville in the central GBR $\left(146^{\circ} 5^{\prime} \mathrm{E}\right.$, $\left.19^{\circ} 1^{\prime} \mathrm{S}\right)$, and from One Tree Island at the southern end of the GBR $\left(152^{\circ} 3^{\prime} \mathrm{E}, 23^{\circ} 4^{\prime} \mathrm{S}\right)$. At Lizard Island 2 independent samples were collected on reefs separated by an average distance of $20 \mathrm{~km}$ : (1) on the fringing reef fronts surrounding Lizard Island and (2) on the exposed reef fronts of 3 reefs on the outer shelf (No Name, Day and Hicks reefs). In the central South Pacific Ocean, samples were collected in American Samoa from the fringing coral reefs of Ofu-Olosega, $\mathrm{Ta}^{\prime} \mathrm{u}$ and Tutuila Islands $\left(170^{\circ} \mathrm{W}, 14^{\circ} 2^{\prime} \mathrm{S}\right)$, and in Moorea in French Polynesia $\left(149^{\circ} 6^{\prime} \mathrm{W}, 1^{\circ} 5^{\prime} \mathrm{S}\right)$. Sampling locations are shown in Fig. 1.

A total of 1537 individuals of Ctenochaetus striatus were speared on scuba and snorkel. On collection, individuals were either processed immediately or placed in an ice-slurry until return to the laboratory for processing on the same day. For each individual, fork length (FL) was measured to the nearest $\mathrm{mm}$. The sagittal pair of otoliths was removed following sectioning of the skull, cleaned and stored dry in lidded 96well trays.

Otolith preparation and determination of age. All age estimates were based on sectioned sagittal otoliths. The annual pattern of increment formation has been validated for a number of acanthurid species, including Ctenochaetus striatus (Choat \& Axe 1996). Daily ring formation has been previously validated for juvenile acanthurids of the same genus (Ctenochaetus binotatus, Lou \& Moltschaniwskyj 1992).

One sagitta of each pair of otoliths was chosen randomly and weighed to the nearest $0.1 \mathrm{mg}$ for adults, and to the nearest $0.01 \mathrm{mg}$ for juveniles. These weights were used to establish the relationship between otolith weight and age. Site-specific regressions of otolith weight on age allowed rapid checking of the precision of reading of the number of annuli and daily increments (Boehlert 1985). A transverse section was obtained by grinding down both rostral and distal ends of the otolith using wet and dry sandpaper or lapping film, resulting in a thin section containing the nucleus. Each section was then covered with clear Crystalbond thermoplastic cement (Aremco) for reading. Annual increments were counted under a stereo dissector, and daily rings under a high-power microscope. Age was estimated as the mean of 3 separate readings provided that the 3 counts did not differ by more than $10 \%$. When readings deviated by more than $10 \%$, the second otolith was processed when available, or else the individual was not included in the age-based analyses. All otolith-increment readings were performed by E. L. Trip.

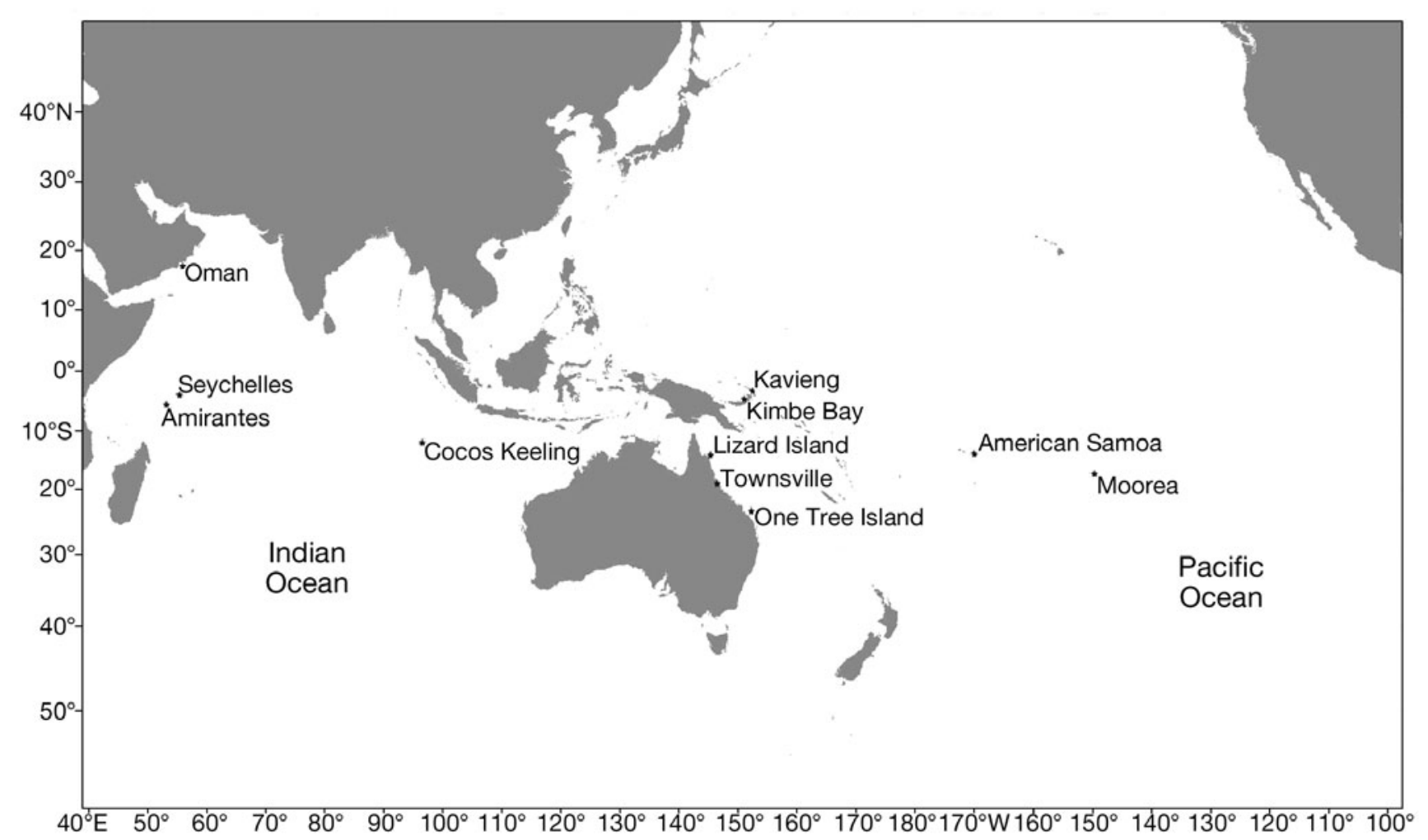

Fig. 1. Sampling locations of Ctenochaetus striatus across the Indo-Pacific region. Two independent samples were collected at Cocos Keeling and Lizard Island, and 3 islands were sampled separately in American Samoa (Tutuila, Ta'u and Ofu-Olosega) 
Modelling of somatic growth and estimation of growth rate. Comparing growth trajectories between populations-limitations of the VBGF equation: Growth in fish is traditionally described using the generalized equation of the von Bertalanffy growth function (VBGF), which adequately describes growth in fish (Cerrato 1990, Chen et al. 1992). The generalised VGBF equation is as follows:

$$
L(t)=L_{\infty}\left\{1-\exp \left[-K\left(t-t_{0}\right)\right]\right\}
$$

where $L(t)$ is estimated mean size-at-age $t_{1} L_{\infty}$ is mean asymptotic size, $K$ is a curvature parameter and $t_{0}$ is the age at which the fish have a theoretical size of zero. However, the biological interpretation of the VBGF parameters $L_{\infty} K$ and $t_{0}$ has often been questioned, and many uncertainties have been raised as to the statistical properties of the parameters when comparing them between populations (Knight 1968, Roff 1980, Ratkowsky 1986, Moreau 1987, Cerrato 1991, Mulligan \& Leaman 1992, Craig 1999). Additionally, the curvature parameter $K$ is not a true growth rate (Cerrato 1991): $K$ is a measure, as a reciprocal of time, of the time taken before the asymptote is (or would be) reached, and a high value of $K$ does not necessarily imply a high rate of growth. These limitations to the VBGF equation were of primary concern for 2 key aspects of the present study: the assessment of early somatic growth, and the statistical comparison of demographic parameters among populations. Therefore, the VBGF equation was re-parameterized after Francis (1988), Moulton et al. (1992), Ewing (2003), and Welsford \& Lyle (2005).

Re-parameterized version of the VBGF equation: The re-parameterized version of the VBGF equation (rVBGF) describes growth in a similar fashion as the traditional VBGF, and is based on 3 parameters, $L(\tau)$, $L(\omega)$ and $L(\mu)$, which express expected average body size at 3 arbitrary ages $\tau, \omega$ and $\mu$. As a result, the biological significance of the parameters allows for a direct comparison of mean size-at-age data between populations. Ages $\tau$ and $\mu$ are chosen arbitrarily within the range of the dataset so as to represent the general form of growth, and $\omega$ is determined by the average age of $\tau$ and $\mu$. The re-parameterized equation of the VBGF is as follows:

$$
L(t)=L(\tau)+\frac{(L(\mu)-L(\tau))\left[1-r\left(2 \frac{t-\tau}{\mu-\tau}\right)\right]}{1-r^{2}}
$$

where $r=\frac{L(\mu)-L(\omega)}{L(\omega)-L(\tau)}$, and $L(t)$ is the average size-atage $t$ to be predicted by the model, provided that $L(\tau)<$ $L(\omega)<L(\mu)$ and $(L(\mu)-L(\omega)) \neq(L(\omega)-L(\tau))$, limitations that affect both the generalised and the re-parameterized VBGF.
Ctenochaetus striatus is characterized by rapid growth in the first year, followed by attainment of asymptotic size by the fifth year in all populations examined to date. In order to compare growth of the study species across geographical scales and locations, 2 key points along the growth trajectory were selected. These were mean size achieved at the end of the first year of growth as an estimate of growth rate, and mean size achieved by year 5 as an estimate of adult body size. In the context of the rVBGF model, age $\tau$ was chosen as year 1, generating an estimate $L(1)$ of mean sizeat-year 1, hereafter referred to as 'age-1 size' or $L(1)$; and age $\mu$ was set at $5 \mathrm{yr}$ old generating an approximation for mean size-at-age 5, the asymptotic size for all populations, hereafter referred to as 'adult size' or $L(5)$. Age $\omega$ was then calculated to be 3 yr old. Thus, the parameters for the rVBGF model in the present study were $L(1), L(3)$ and $L(5)$; however, we focused on the parameters $L(1)$ and $L(5)$.

The rVBGF model was fitted through the observed data of each sample, and the best-fit model describing each dataset was determined by minimizing the negative $\log$ of the likelihood given a probability density function with a Poisson distribution (Kimura 1980, Haddon 2001). For each sample, the rVBGF model was fitted by constraining the $y$-intercept of the curve to approximate size at settlement $L_{0}$ (Kritzer et al. 2001), with $L_{0}=47 \mathrm{~mm}$ FL (based on estimates from Stobutzki \& Bellwood 1997).

Estimation of longevity. Mean maximum age, mean $T_{\max }$ was calculated as the average age of the oldest $10 \%$ of individuals in each sampled population (modified from Choat \& Robertson 2002).

Mean sea surface temperature. Mean sea surface temperature $\left(\mathrm{SST}^{\circ}{ }^{\circ} \mathrm{C}\right)$ was used to describe the latitudinal environmental gradient (see Table 1). SST was calculated based on long-term NOAA data from 1971 to 2000 (January to December) by estimating the average annual temperature observed at each location (www.cdc.noaa.gov/cgi-bin/DataAccess.pl?DB_dataset $=$ NOAA+Extended+Reconstructed+SST\&DB_variable $=$ Sea + Surface + Temperature \&DB_statistic $=$ Long + Term + Mean\&DB_tid=3955\&DB_did=63\&DB_vid=1294). Years were selected so as to cover the life spans of the longest lived individuals across all sampled populations.

Analysis of spatial variation in longevity, age-1 size and adult size. The latitudinal distribution and area of reef habitats differs substantially between the Indian and Pacific oceans (Spalding \& Grenfell 1997). This confounded attempts to develop separate comparative analyses of demographic variation over geographically equivalent latitudinal gradients in each ocean basin. Therefore, a multiple regression analysis was used to detect trends in growth, size and longevity across the entire sampled range of the study species including 


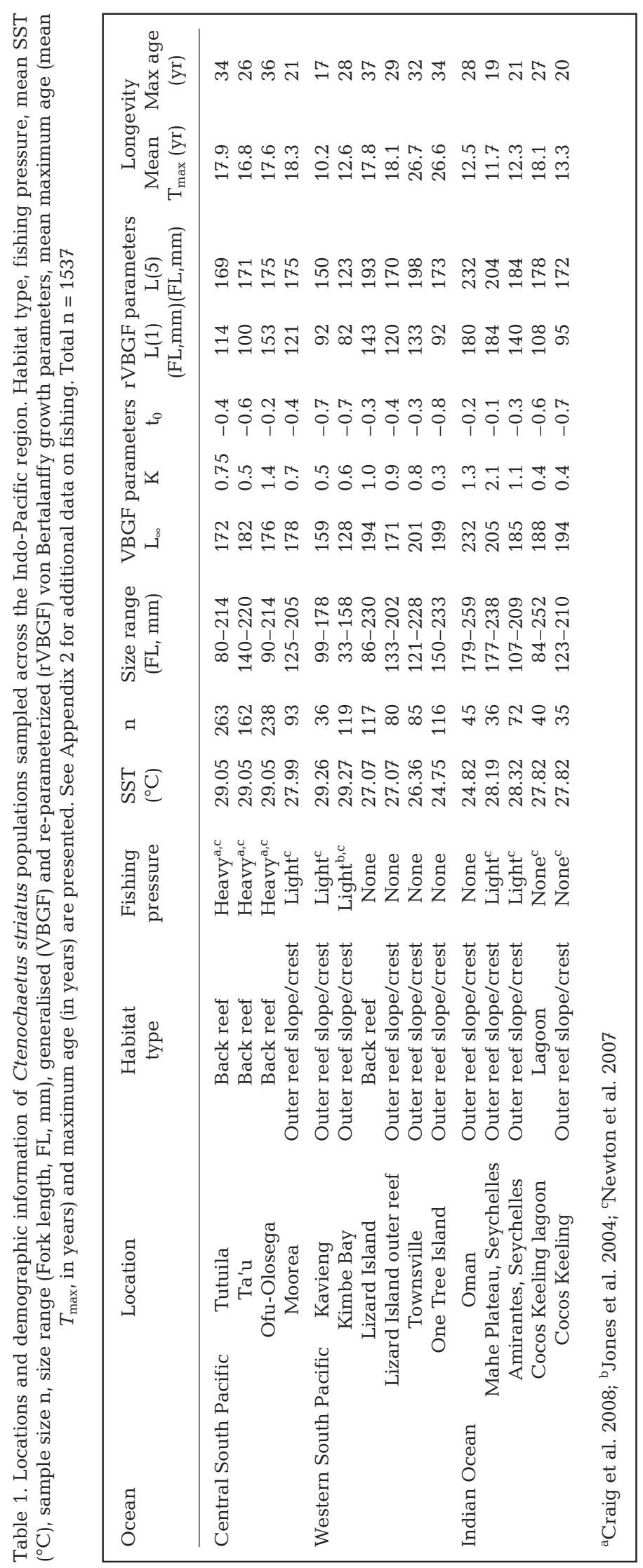

the longitudinal and latitudinal elements of the sampling program.

A separate multiple linear regression analysis was performed for each of the following 3 dependent variables: longevity (mean $T_{\max }$ ), age-1 size $[L(1)]$ and adult size $[L(5)]$. In each analysis, the following 2 continuous predictor variables were included: longitude, and mean SST. SST was a proxy for latitudinal location, as temperature varied systematically along this gradient. These analyses were designed to detect trends in longevity, growth rate and body size in relation to longitude and varying temperature. In order to avoid redundancy in samples at the same location (Lizard Island and Cocos Keeling each have 2 samples), and in an effort to standardise by habitat as far as possible, the following samples were excluded from these 3 analyses: Lizard Island inner reefs and Cocos Keeling lagoon. The model tested was of the form:

$$
Y=a_{0}+a_{1}(\text { longitude })+a_{2}(\mathrm{SST})+\text { error }
$$

where $Y$ is the dependent variable tested (longevity, age-1 size or adult size, respectively), and $a$ is the corresponding partial regression coefficient; $a_{0}$ represents the intercept, $a_{1}$ the effect of longitude when SST remains constant, and $a_{2}$ the effect of SST when longitude remains constant.

For each analysis, the null hypothesis tested was that each partial regression coefficient equalled zero. Assumptions of colinearity, homogeneity of variances and normality were checked. Firstly, a matrix of correlation coefficients showed that, in each case, the 2 predictor variables longitude and SST were not correlated $\left(\mathrm{r}^{2}=0.2953, \mathrm{p}=\right.$ 0.327 , tolerance $=0.9128$ ). Secondly, observed values of each dependent variable were normally distributed and spread of the residuals was reasonably constant across predicted values. In each of the 3 analyses the regression model chosen to best represent the data was linear, as the adjusted $\mathrm{r}^{2}$ value did not increase significantly when using non-linear models.

The mean and variance in longevity and body size were estimated at 2 spatial scales, between oceans and between locations within oceans. The comparisons were made using 2-way nested ANOVAs with oceans treated as a fixed factor, and locations a random factor nested within oceans. Maximum age data used in the analysis were the $10 \%$ oldest individuals at each location sampled. Size data used in the analysis were individuals aged 5 to 7 yr. Adult size was achieved by 
$5 \mathrm{yr}$ in all populations sampled; 5 to $7 \mathrm{yr}$ old age classes were well sampled at all locations. As in the regression analyses, Lizard Island inner reefs and Cocos Keeling lagoon were excluded from the analyses so as to avoid redundancy in samples at the same location. The 2 nested ANOVAs showed an unbalanced design, with unequal numbers of levels of the nested factor (location) within each level of the higher factor (ocean) for both analyses, and an unequal number of replicates across groups. The missing cells were taken into account by using a Type $\mathrm{V}$ sum of squares for calculation of the F-ratio, and nested ANOVA is relatively robust to unbalanced designs (Quinn \& Keough 2002). Care was taken to comply with assumptions of normality and homogeneity of variance, the latter being particularly important in the analysis of unbalanced nested designs (Quinn \& Keough 2002).

There are relatively few reefs in the Indian Ocean compared to the Pacific Ocean, which resulted in an unbalanced sampling design with 4 locations in the Indian Ocean and 9 in the Pacific. In addition, logistics on isolated Indian Ocean reefs made it difficult to collect large samples at each location. To guard against comparisons being compromised by unbalanced sampling designs, 2 subsampling procedures were used to check for (1) the effect of an unequal number of locations sampled in each ocean, and (2) the effect of differing sample sizes across locations sampled in both oceans. The results were consistent with those found in the original nested analyses (Appendix 1).

Variance components were then calculated (from the nested ANOVAs based on a balanced sampling design) to estimate the relative proportion of the overall variation in longevity and adult body size that could be explained by each spatial scale (ocean, location). Locations included in the Pacific Ocean were Tutuila, Moorea, Townsville and Kimbe Bay (one of the combinations in Pacific Ocean locations was randomly picked; there was no effect on the results of the combination of locations included, Appendix 1). Variance components were calculated following Quinn \& Keough (2002).

Impact of fishing pressure and habitat type on demographic variables. To examine the potentially confounding effect of diverse fishing pressures of our study species and habitat types across our sampling sites on our results, each location was assigned a level of fishing pressure and habitat type (see Table 1, Appendix 2).

Fishing levels: Separate 1-way ANOVAs were used to test for the effect of the categorical factor 'fishing level' on each of the 3 dependent variables: longevity (mean $T_{\max }$ ), age-1 size $[L(1)]$ and adult size $[L(5)]$. There was no significant difference in homogeneity of variance for $L(1)$ or $L(5)$, and residuals were normally distributed. The dependent variable mean $T_{\max }$ was log10-transformed to meet assumptions of normality of variance and normality of distribution of the residuals.

Habitat types: Habitat types were assigned as in Connolly et al. (2005) based on on-site inspection of the structure of the reefs where samples were collected and on literature reports. Three habitat categories were assigned: (1) outer reef slope/crest, where reefs are exposed to ocean conditions and prevailing winds; (2) back reef, which are reef slopes but on the sheltered side of reefs; and (3) lagoonal environments, which are enclosed and sheltered (see Table 1). A separate 1-way ANOVA was performed for each of the 3 dependent variables, mean $T_{\max }, L(1)$ and $L(5)$, to examine the effect of the categorical factor 'habitat type'. In each case there was no significant difference in homogeneity of variance across groups for both size variables, $L(1)$ and $L(5)$, and residuals were reasonably normally distributed. Mean $T_{\max }$ was power-transformed to meet the assumptions of homogeneity of variance and normal distribution of the residuals. All analyses were performed using Statistica 6.1 (StatSoft).

\section{RESULTS}

Analysis of the relationship between size and age in 15 populations of Ctenochaetus striatus from the Indian Ocean (5 populations), the western Pacific Ocean (6 populations) and the central Pacific Ocean (4 populations) revealed that asymptotic growth was consistent across locations and geographical scales (Fig. 2). In all sampled populations there was a fast initial growth, which reduced sharply with an increase in age. In most populations, asymptotic size was achieved within the first 10 to $20 \%$ of the life span, resulting in a decoupling of size and age in adults. This form of growth is characteristic of many coral reef fishes, including acanthurid species (Choat \& Robertson 2002), a number of lutjanids (Newman et al. 2000) and some chaetodontids (Berumen 2005).

While all populations displayed a consistent form of growth, there was considerable variation in the relationship between size and age among locations. Shifts among populations could be observed along both the $x$ - and $y$-axes of the size-at-age relationships, reflecting variation in longevity, mean maximum size and steepness of the ascending part of the growth trajectory or growth rate (Fig. 2). Variation in the structure of these curves identified differences among populations in the parameters of longevity, age-1 size and adult (age-5) size.

Regression analyses on longevity (mean $T_{\max }$ ), age1 size $[L(1)]$ and adult size $[L(5)]$ revealed contrasting effects of longitude and mean SST. Both longitude and SST significantly influenced longevity, while 
Indian Ocean
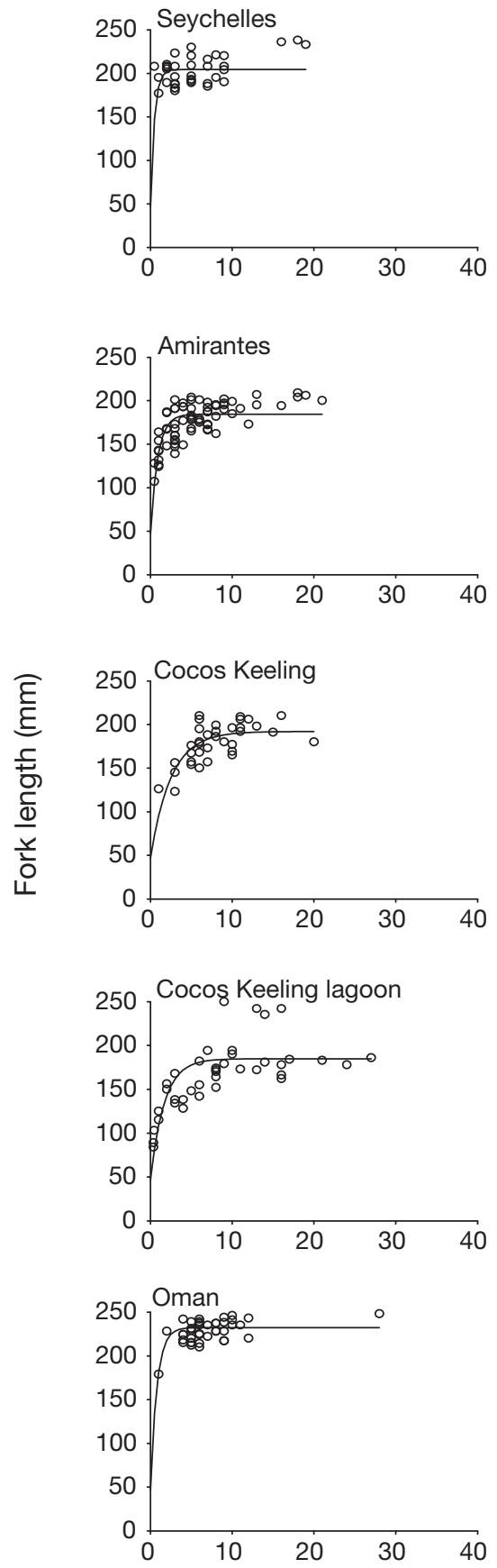

West Pacific Ocean
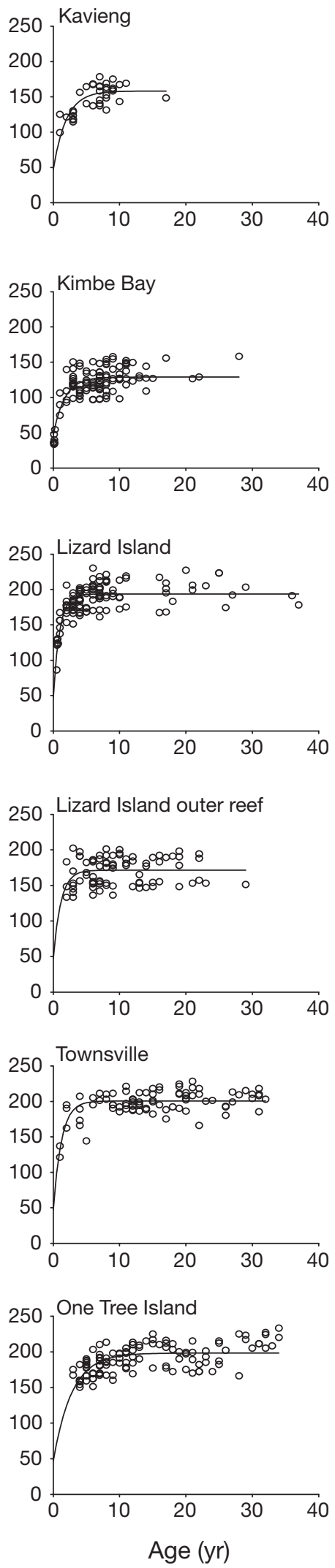
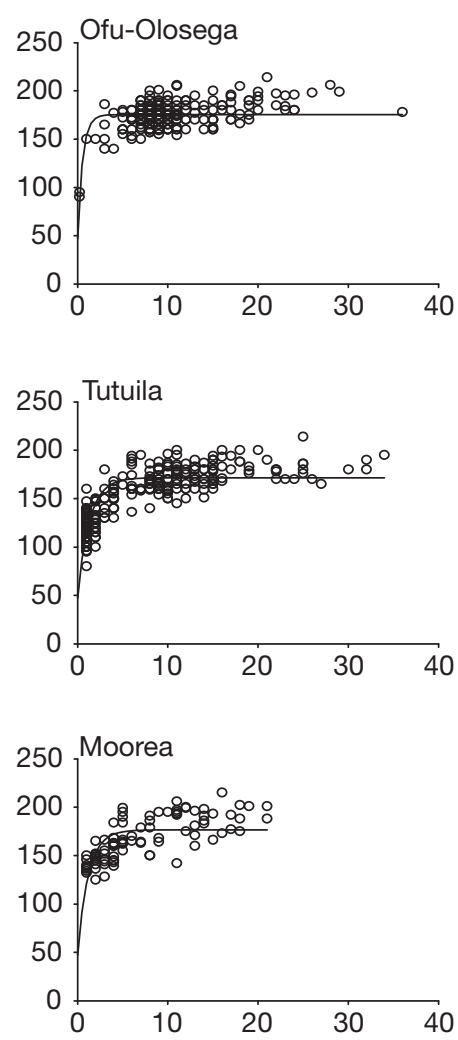

Central Pacific Ocean

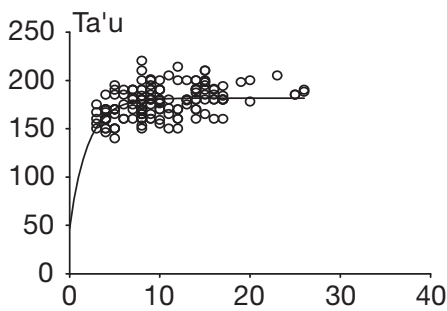

Fig. 2. Ctenochaetus striatus. Size-at-age relationships illustrating growth of $C$. striatus across the Indo-Pacific region. (o) Observed size-at-age of individual fish sampled; lines represent best-fit rVBGF (reparameterized von Bertalanffy growth function) growth trajectories 
Table 2. Results of linear multiple regression analyses performed on Ctenochaetus striatus longevity (mean $\left.T_{\max }\right)$, age-1 size [L(1)] and adult size $[L(5)]$, to examine the effect of longitude $\left({ }^{\circ} \mathrm{E}\right)$ and mean SST $\left({ }^{\circ} \mathrm{C}\right.$, as a proxy for latitude). $\mathrm{n}=13$ for each analysis performed. $t$ shows value of the $t$-test statistic. Semi-partial correlation coefficients indicate the unique contribution by the respective predictor variable to explaining the total variance. Multiple $\mathrm{R}^{2}$ represents the amount of variation explained by the overall regression model fitted for each dependent variable. Bold p-values are significant at the 0.05 level

\begin{tabular}{|c|c|c|c|c|c|c|c|}
\hline $\begin{array}{l}\text { Variable } \\
\text { tested }\end{array}$ & $\begin{array}{l}\text { Predictor } \\
\text { variable }\end{array}$ & $\begin{array}{c}\text { Regression } \\
\text { coefficient } \pm \mathrm{SE}\end{array}$ & $t$ & $\mathrm{p}$ & $\begin{array}{c}\text { Semi-partial } \\
\text { correlation coefficient }\end{array}$ & Tolerance & Multiple $\mathrm{R}^{2}$ \\
\hline Mean $T_{\max }$ & $\begin{array}{l}\text { Intercept } \\
\text { Longitude } \\
\text { SST }\end{array}$ & $\begin{array}{l}71.46 \pm 16.72 \\
0.075 \pm 0.020 \\
-2.33 \pm 0.62\end{array}$ & $\begin{array}{r}4.27429 \\
3.71602 \\
-3.75181\end{array}$ & $\begin{array}{l}<0.01 \\
<0.01 \\
<0.01\end{array}$ & $\begin{array}{r}0.66 \\
-0.67\end{array}$ & $\begin{array}{l}0.912 \\
0.912\end{array}$ & 0.62 \\
\hline$L(1)$ & $\begin{array}{l}\text { Intercept } \\
\text { Longitude } \\
\text { SST }\end{array}$ & $\begin{array}{c}229.67 \pm 150.08 \\
-0.38 \pm 0.18 \\
-2.01 \pm 5.59\end{array}$ & $\begin{array}{r}1.53028 \\
-2.10648 \\
-0.35923\end{array}$ & $\begin{array}{l}0.1569 \\
0.0614 \\
0.7268\end{array}$ & $\begin{array}{l}-0.53 \\
-0.091\end{array}$ & $\begin{array}{l}0.912 \\
0.912\end{array}$ & 0.22 \\
\hline$L(5)$ & $\begin{array}{l}\text { Intercept } \\
\text { Longitude } \\
\text { SST }\end{array}$ & $\begin{array}{c}424.79 \pm 97.37 \\
-0.24 \pm 0.12 \\
-7.82 \pm 3.62\end{array}$ & $\begin{array}{r}4.36275 \\
-1.99968 \\
-2.15696\end{array}$ & $\begin{array}{r}<\mathbf{0 . 0 1} \\
0.0734 \\
0.0563\end{array}$ & $\begin{array}{l}-0.42 \\
-0.46\end{array}$ & $\begin{array}{l}0.912 \\
0.912\end{array}$ & 0.46 \\
\hline
\end{tabular}

there was no significant effect of either predictor variables on age-1 size or adult size (Table 2). There was a significant linear relationship between longevity and longitude ( $t$-test; $t=3.71602, \mathrm{p}<0.01)$, indicating that longevity increased linearly on a gradient from the western Indian Ocean to the central Pacific Ocean in the populations sampled (Table 2, Fig. 3a). There was also a significant negative linear relationship between longevity and SST (used as a proxy for latitude) $(t=-3.75181, \mathrm{p}<0.01)$ (Table 2, Fig. 3a). Together, longitude and SST explained $62 \%$ of the total variance in longevity in the populations sampled (Table 2).

ANOVA of raw maximum age data confirmed the presence of significant differences in longevity among ocean basins (Table 3). Differences in longevity between the Indian and Pacific oceans (on an oceanic scale) explained $47 \%$ of the variation in longevity among populations sampled (Fig. 4). Longevity also varied significantly among locations independently of ocean, with this accounting for a further $16 \%$ of the variation in longevity (Fig. 4).

Table 3. Results of nested ANOVAs comparing longevity (maximum age, in years) and adult body size (fork length of 5 to $7 \mathrm{yr}$ olds, in $\mathrm{mm}$ ) of Ctenochaetus striatus, based on raw age and size data across spatial scales (ocean, location). Location was nested within ocean. Bold p-values are significant at the 0.05 level

\begin{tabular}{|lcccrrc|}
\hline Variable & Effect & SS & MS & df & $F$ & $p$ \\
\hline Longevity & Intercept & 22646.85 & 22646.85 & 1 & 164.0748 & $<\mathbf{0 . 0 0 1}$ \\
& Ocean & 683.92 & 683.92 & 1 & 5.1132 & $<\mathbf{0 . 0 5}$ \\
& Location (Ocean) & 2766.03 & 251.46 & 11 & 17.8139 & $<\mathbf{0 . 0 0 1}$ \\
& Residual & 1835.05 & 14.12 & 130 & & \\
Adult size & Intercept & 5623339 & 5623339 & 1 & 750.2943 & $<\mathbf{0 . 0 0 1}$ \\
& Ocean & 35894 & 35894 & 1 & 4.7694 & 0.0512 \\
& Location (Ocean) & 109410 & 9946 & 11 & 51.1590 & $<\mathbf{0 . 0 0 1}$ \\
& Residual & 48411 & 249 & 194 & & \\
\hline
\end{tabular}

In contrast, no significant trends in growth or adult size were observed in relation to either longitude or latitude (temperature) (Table 2). Longitude and SST explained $22 \%$ of the variation in age- 1 size and $46 \%$ of the variation in adult size (Table 2). ANOVA of raw adult body size data confirmed that there was no significant difference in adult body size between the Indian and the Pacific oceans, and revealed that variation in size across populations sampled was explained primarily by differences among locations (Table 3), which explained 58\% of the variation (Fig. 4).

Analysis of potential confounding effects on our results included those of differing fishing intensities and habitat types across populations sampled. Separate 1-way ANOVAs were performed on each of the 3 demographic variables of age-1 size, adult size and longevity, testing for the effects of fishing level and habitat type, respectively. We found no significant effect of fishing pressure on age-1 size [ $L(1)$ : 1 -way ANOVA, $F_{2,10}=0.0017, \mathrm{p}>$ 0.05], adult size [ $\left.L(5): F_{2,10}=0.9445, \mathrm{p}>0.05\right]$ or longevity $\left(\log 10\right.$ mean $\left.T_{\text {max }}: F_{2,10}=2.612, p>0.05\right)$, suggesting that differences found in body size across locations, and differences in longevity across longitudinal and latitudinal scales, were not affected by differences in fishing intensity across our sampling locations. Similarly, we found no significant effect of habitat type on any of the 3 demographic variables. There was no significant difference in age-1 size $\left(F_{1,11}=0.0032, \mathrm{p}>\right.$ $0.05)$, adult size $\left(F_{1,11}=0.1335, \mathrm{p}>0.05\right)$ or longevity (exp mean $T_{\max }: F_{1,11}=$ $0.6338, \mathrm{p}>0.05$ ), confirming that the patterns of differences in body size and longevity found for Ctenochaetus striatus were not the result of differing habitat types across sampling sites. 

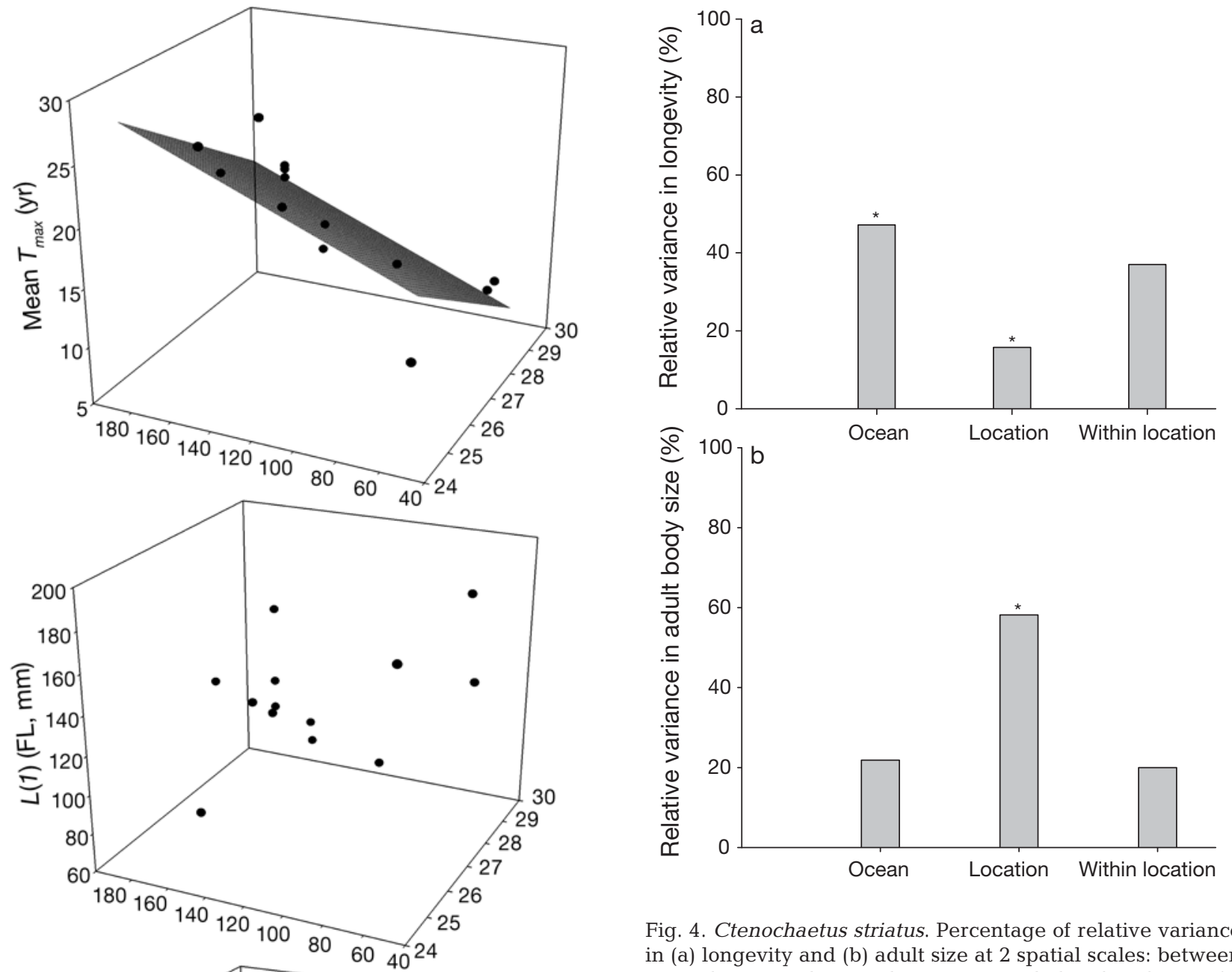

Fig. 4. Ctenochaetus striatus. Percentage of relative variance in (a) longevity and (b) adult size at 2 spatial scales: between ocean basins and across locations sampled within the Pacific and Indian Oceans. Within location represents the unexplained residual error within each level of the nested factor. *: Significant result of 2-way ANOVA performed for each of the 2 variables, $\mathrm{p}<0.05$

\section{DISCUSSION}

The analysis of 15 populations of Ctenochaetus striatus sampled across $17360 \mathrm{~km}$, or $83 \%$ of its longitudinal range, and $2280 \mathrm{~km}$, or $66 \%$ of its latitudinal range, revealed several distinct trends in age structure, growth rate and size. These were manifested at different spatial scales. At the greatest (longitudinal) spatial scale, the most consistent signal in the dataset was a trend in mean maximum age (longevity). Analysis over the longitudinal gradient revealed a trend in longevity

Fig. 3. Ctenochaetus striatus. (a) Relationship between longitude $\left({ }^{\circ} \mathrm{E}\right)$, mean $\operatorname{SST}\left({ }^{\circ} \mathrm{C}\right.$, as a proxy for latitude) and longevity (mean $T_{\max }$ ) of $C$. striatus across the Indian and Pacific Ocean basins. Regression model fitted is mean $T_{\max }=71.46$ $( \pm 16.72)+0.075( \pm 0.020)$ (Longitude) $-2.33( \pm 0.62)(\mathrm{SST})$, $\mathrm{R}^{2}=0.62$. (b) Relationship between longitude, mean SST and age-1 size $(L(1))$. (c) Relationship between longitude, mean SST and adult size $(L(5)) . F L=$ fork length from the western Indian Ocean to the central Pacific Ocean, with Indian Ocean populations tending to be shorter lived than Pacific populations. Latitudinal large-scale sampling revealed a negative relationship between longevity and mean SST. This pattern is consistent with that observed in a tropical Atlantic acan- 
thurid (Robertson et al. 2005a), where longevity was correlated with decreasing SST and increasing seasonality. In contrast, we detected no large-scale longitudinal or latitudinal patterns in either growth rate or adult size. Growth and size varied primarily at the scale of locations within each ocean, with all populations displaying a strongly asymptotic growth pattern typical of acanthurids.

Robertson et al. (2005a) detected a negative relationship between growth of the Atlantic surgeonfish Acanthurus bahianus and SST on a large geographic scale. While consistent with latitudinal counter-gradient variation (Conover et al. 2006), the effect was only manifested in early growth phases. There was also evidence of more localized variation in growth associated with habitat structure, with the extent of differences in growth between 2 habitats on one reef spanning much of the latitudinal range of variation in growth. Localized variation in growth rates and size structures might be pervasive in reef fishes. Indeed, the present study detected no latitudinal trend in growth rate in Ctenochaetus striatus. Most of the variation in adult size in this species was related to locality $(58 \%)$, the only factor to show a significant effect, and within-location $(20 \%)$; variation in body size between oceans accounted for only $22 \%$ of the variation. Although the sampling habitat was standardized as far as possible, subtle differences in habitat structure may have contributed to the variation in size and growth rate observed in different locations in the present study.

While variation in growth rate and size structure of Ctenochaetus striatus was localized, variation in longevity occurred at a large geographical (latitudinal) scale. A number of factors could drive this latitudinal trend including temperature, seasonality, productivity and prevailing mortality regimes. For some teleosts, increases in life span are associated with increasing variation in annual reproductive outputs and recruitment, so that long-lived species manifest a highly uneven distribution of age classes (Murphy 1968). At high latitudes there are reduced seasonal windows for spawning compared with low latitude populations of the same species (Robertson 1991, Kokita 2004, Srinivasan \& Jones 2006). At present the relationship between reproduction, recruitment and life span is unclear for reef fishes. Robertson et al. (2005a) examined variation in longevity of an Atlantic acanthurid with respect to recruitment variation and found no evidence for such a relationship. However, Robertson et al. (2005a) did identify a relationship between the seasonality of reproductive output and longevity suggesting a trade-off between longevity and reproduction (Stearns 1992).

Longer spawning periods will increase reproductive costs, leading to reduced allocations of energy for growth and somatic maintenance (Robertson et al. 2005a, Ruttenberg et al. 2005). Ruttenberg et al. (2005) demonstrated that, for a subtropical reef fish, temperature explained a significant proportion of reproductive output per unit of biomass, with fish from warmer temperature habitats manifesting increased reproductive outputs, lower growth rates and shorter life spans relative to those from colder water habitats. However, establishing the relationship between reproductive output and other demographic characteristics will be complex, as increased reproductive outputs may be both a response to and a cause of increased mortality (Stearns 1992, Ruttenberg et al. 2005). Ruttenberg et al. (2005) concluded that temperature-mediated reproductive output was a cause of increased mortality, arguing that populations with shorter reproductive seasons would allocate less of their annual energy budgets to reproduction, resulting in larger, older animals. The complexity of the relationship between lifespan and relative investments in somatic maintenance versus reproduction and the impact of feeding regimes have been recently explored by Inness \& Metcalfe (2008). In addition, lower temperature populations will experience reduced metabolic rates and maintenance costs (Clarke \& Johnston 1999). This explanation is consistent with the limited number of studies that focus on age-based approaches to reef fish life histories.

The emerging picture of reef fish demographic variation identifies the importance of integrating reproductive, growth and mortality schedules. However, estimates of annual or life-time reproductive outputs for most reef fishes will be difficult to obtain. Many populations, including acanthurids, manifest extended seasonal spawning periods with daily spawning migrations and episodes of group spawning. Estimating individual contributions to both seasonal and life-time fecundities has been accomplished in only a few cases with tropical reef fishes (Doherty 1983, Ross 1983, Hoffman \& Grau 1989, Warner et al. 1995). Such analyses will be further complicated by the possibility that reduced seasonal opportunities for reproduction may lead to compensatory increases in reproductive output in high-latitude populations (Kokita 2004).

Multi-scale sampling has revealed the complexity of demographic variation in reef fishes, especially in longevity. Although significant trends occur over broad spatial scales, variation in longevity may also occur at very localized scales. Gust et al. (2002) and Gust (2004) identified a pattern of consistent differences in longevities, growth rates and sex-specific maturation of reef fishes in genetically connected populations (Dudgeon et al. 2000) separated by $12 \mathrm{~km}$. Individuals of the study populations on exposed outer barrier reefs had both significantly higher mortalities and reduced growth rates as well as a significantly 
reduced age at first reproduction. Gust et al. (2002) attributed the higher mortality rates to the greater abundance of predators on exposed reef sites. This resulted in populations with a high turnover rate in which changes in reproductive output were a consequence, not a cause, of increased mortality.

A consistent theme in much of the recent coral reef literature concerns overfishing, and the tacit assumption that locality and regional scale patterns of demographic variation are no more than reflections of the geography of anthropogenic influences. Although fishing has obvious impacts on abundance patterns in coral reef species, it has proved more problematical to demonstrate impacts on longevity (Choat et al. 2003, Robertson et al. 2005b). This is illustrated in the present study in that longevity in American Samoa (16.8 to $17.9 \mathrm{yr}$ ), an overfished, collapsed fishery (Newton et al. 2007) that heavily targets Ctenochaetus striatus (Craig et al. 2008), is similar to that on the GBR (17.8 to $26.7 \mathrm{yr}$ ), where there is no fishery for that species, and greater than that in northern PNG (10.2 to $12.6 \mathrm{yr}$ ), an underexploited fishery (Newton et al. 2007) (Appendix 2).

It is clear that the underlying causation of demographic variation in reef fishes will involve both evolutionary and mechanistic processes. Resolution of the relationship between life history features and environmental variation (both biological and physical) will require 2 things. First, an experimental approach employing common-garden experiments that subject individuals of known parentage and provenance to controlled manipulation of environmental variables and resource levels (Conover 1992, Kokita 2003, 2004). However, there are formidable technical obstacles to such experiments, including the development of culturing programs for tropical groups such as acanthurids and scarines, and the substantial life spans of these and other tropical species. Second, better estimates of reproductive outputs including life time fecundities are required, but will be difficult to obtain for long-lived species with multiple spawning episodes. Realistically, the most productive present approach is to obtain better information on the magnitude and direction of multi-scale demographic trends in order to frame more rigorous and testable hypotheses.

Acknowledgements. This research was supported through the National Geographic Grant Program to J.H.C. and D.R.R., Queensland Government/Smithsonian Institution (STRI) Collaborative Funding to J.H.C. and D.R.R., CRC Reef Augmentative Grant Program to E.L.T. and James Cook University Internal Funding to J.H.C. and E.L.T. Sampling at remote locations was facilitated by cooperative research programs involving Sultan Qaboos University Oman (J. McIlwain), the Seychelles Fisheries Authority (J. Robinson), Lizard Island and One Tree Island Research Stations, Mahonia Research
Station Kimbe Bay, and Parks Australia Cocos Keeling Island (W. Murray, R. Thorne). We also gratefully acknowledge support from the Department of Marine and Wildlife Resources, American Samoa and permission to use the datasets from this region. The authors thank W. D. Robbins, J. L. Ackerman and M. Berumen for assistance with field collections, R. Arthur, W. D. Robbins, J. L. Ackerman and T. Denis for assistance with analysis. We also acknowledge assistance from R. I. C. C. Francis for help with analysis of growth data. The study benefited from discussions with J. L. Ackerman, P. Craig, R. Hamilton, M. G. Meekan, W. D. Robbins and G. Russ. Comments by an anonymous referee greatly assisted in the revision of this manuscript. Collections were made under GBRMPA Permit no. G03/3871.1 to the School of Marine Biology, James Cook University.

\section{LITERATURE CITED}

Ashton KG, Feldman CR (2003) Bergmann's rule in non-avian reptiles: turtles follow it, lizards and snakes reverse it. Evolution 57:1151-1163

Berumen ML (2005) The importance of juveniles in modelling growth: butterflyfish at Lizard Island. Environ Biol Fishes 72:409-413

Boehlert G (1985) Using objective criteria and multiple regression models for age determination in fishes. Fish Bull 83:103-117

Cerrato RM (1990) Interpretable statistical tests for growth comparisons using parameters in the von Bertalanffy equation. Can J Fish Aquat Sci 47:1416-1426

Cerrato RM (1991) Analysis of nonlinearity effects in expected-value parameterizations of the von Bertalanffy equation. Can J Fish Aquat Sci 48:2109-2117

Chen Y, Jackson DA, Harvey HH (1992) A comparison of von Bertalanffy and polynomial functions in modelling fish growth data. Can J Fish Aquat Sci 49:1228-1235

Choat JH, Axe LM (1996) Growth and longevity in acanthurid fishes: an analysis of otolith increments. Mar Ecol Prog Ser $134: 15-26$

Choat JH, Robertson DR (2002) Age-based studies. In: Sale PF (ed) Coral reef fishes. Academic Press, San Diego, CA, p 57-80

Choat JH, Robertson DR, Ackerman JL, Posada JM (2003) An age-based demographic analysis of the Caribbean stoplight parrotfish Sparisoma viride. Mar Ecol Prog Ser 246: 265-277

Clarke A, Johnston NM (1999) Scaling of metabolic rate with body mass and temperature in teleost fish. J Anim Ecol 68:893-905

Connolly SR, Hughes TP, Bellwood DR, Karlson RH (2005) Community structure of corals and reef fishes at multiple scales. Science 309:1363-1365

Conover DO (1990) The relation between capacity for growth and length of growing season: evidence for and implications of countergradient variation. Trans Am Fish Soc 119:416-430

Conover DO (1992) Seasonality and the scheduling of life history at different latitudes. J Fish Biol 41:161-178

Conover DO, Present TMC (1990) Countergradient variation in growth rate: compensation for length of the growing season among Atlantic silversides from different latitudes. Oecologia 83:316-324

> Conover DO, Clarke LM, Munch SB, Wagner GN (2006) Spatial and temporal scales of adaptive divergence in marine fishes and the implications for conservation. J Fish Biol 69:21-47 
Craig PC (1999) The von Bertalanffy growth curve: when a good fit is not good enough. Naga 22:28-29

Craig P, Green A, Tuilagi F (2008) Subsistence harvest of coral reef resources in the outer islands of American Samoa: modern, historic and prehistoric catches. Fish Res 89:230-240

Doherty PJ (1983) Diel, lunar and seasonal rhythms in the reproduction of two tropical damselfishes: Pomacentrus flavicauda and P. wardi. Mar Biol 75:215-224

Dudgeon CL, Gust N, Blair D (2000) No apparent genetic basis to demographic differences in scarid fishes across the continental shelf of the great barrier reef. Mar Biol 137:1059-1066

Ewing GP (2003) Spatial and temporal variation in growth and age composition of the temperate wrasse Notolabrus fucicola in Tasmanian waters. MSc Thesis, Tasmanian Aquaculture and Fisheries Institute, School of Aquaculture, University of Tasmania

Francis RICC (1988) Maximum likelihood estimation of growth and growth variability from tagging data. $\mathrm{N} \mathrm{Z} \mathrm{J}$ Mar Freshw Res 22:43-52

> Gust N (2004) Variation in the population biology of protogynous coral reef fishes over tens of kilometers. Can J Fish Aquat Sci 61:205-218

Gust N, Choat JH, Ackerman JL (2002) Demographic plasticity in tropical reef fishes. Mar Biol 140:1039-1051

Haddon M (2001) Modelling and quantitative methods in fisheries. CRC Press, Boca Raton, FL

> Hoffman KS, Grau EG (1989) Daytime changes in oocyte development with relation to the tide for the Hawaiian saddleback wrasse, Thalassoma duperrey. J Fish Biol 34: 529-546

Inness CLW, Metcalfe B (2008) The impact of dietary restriction, intermittent feeding and compensatory growth on reproductive investment and lifespan in a short-lived fish. Proc R Soc Lond B 275:1703-1708

Kaly UL, Opnai JL (2005) Small scale fisheries in New Ireland province (PNG): landing, market and buyer surveys in Kavieng. Tech Rep National Fisheries Authority, CFMDP Project, available at http://bluesquid.net

Kimura DK (1980) Likelihood methods for the von Bertalanffy growth curve. Fish Bull 77:765-776

Kingsolver JG, Huey RB (2008) Size, temperature and fitness: three rules. Evol Ecol Res 10:251-268

Knight W (1968) Asymptotic growth: an example of nonsense disguised as mathematics. J Fish Res Board Can 25: 1303-1307

Kokita T (2003) Potential latitudinal variation in egg size and number of a geographically widespread reef fish, revealed by common-environment experiments. Mar Biol 143: 593-601

Kokita T (2004) Latitudinal compensation in female reproductive rate of a geographically widespread reef fish. Environ Biol Fishes 71:213-234

Kritzer JP, Davies CR, Mapstone BD (2001) Characterizing fish populations: Effects of sample size and population structure on the precision of demographic parameter estimates. Can J Fish Aquat Sci 58:1557-1568

Lou DC, Moltschaniwskyj NA (1992) Daily otolith increments in juvenile tropical parrotfishes and surgeonfishes. Aust J Mar Freshw Res 43:973-981

Meekan MG, Ackerman JL, Wellington GM (2001) Demography and age structures of coral reef damselfishes in the tropical eastern Pacific Ocean. Mar Ecol Prog Ser 212: 223-232

Moreau J (1987) Mathematical and biological expression of growth in fishes: Recent trends and further developments. In: Summerfelt RC, Hall GE (eds) Age and growth of fish.
Iowa State University Press, Ames, IA, p 81-113

> Moulton PL, Walker TI, Saddlier SR (1992) Age and growth studies of gummy shark Mustelus antarcticus Gunther, and school shark Galeorhinus galeus (Linnaeus), from southern Australian waters. Aust J Mar Freshw Res 43: 1241-1267

> Mulligan TJ, Leaman BM (1992) Length-at-age analysis: Can you get what you see? Can J Fish Aquat Sci 49:632-643

Murphy GI (1968) Pattern in life history and the environment. Am Nat 102:391-403

Newman SJ, Cappo M, Williams DM (2000) Age, growth and mortality of the stripey, Lutjanus carponotatus (Richardson) and the brown-stripe snapper, L. vitta (Quoy and Gaimard) from the central Great Barrier Reef, Australia. Fish Res 48:263-275

Newton K, Cote IM, Pilling GM, Jennings S, Dulvy NK (2007) Current and future sustainability of island coral reef fisheries. Curr Biol 17:655-658

Quinn GP, Keough MJ (2002) Experimental design and data analysis for biologists. Cambridge University Press, Cambridge

Randall JE, Clements KD (2001) Second revision of the surgeonfish genus Ctenochaetus (Perciformes: Acanthuridae), with descriptions of two new species. Indo-Pac Fish 32:1-39

Ratkowsky DA (1986) Statistical properties of alternative parameterizations of the von Bertalanffy growth curve. Can J Fish Aquat Sci 43:742-747

Robertson DR (1991) The role of adult biology in the timing of spawning of tropical reef fishes. In: Sale PF (ed) The ecology of fishes on coral reefs. Academic Press, San Diego, CA, p 356-382

- Robertson DR, Ackerman JL, Choat JH, Posada JM, Pitt J (2005a) Ocean surgeonfish Acanthurus bahianus. I. The geography of demography. Mar Ecol Prog Ser 295:229-244

Robertson DR, Choat JH, Posada JM, Pitt J, Ackerman JL (2005b) Ocean surgeonfish Acanthurus bahianus. II. Fishing effects on longevity, size and abundance? Mar Ecol Prog Ser 295:245-256

Roff DA (1980) A motion for the retirement of the von Bertalanffy function. Can J Fish Aquat Sci 37:127-129

Ross JM (1983) Annual, semilunar, and diel reproductive rhythms in the Hawaiian labrid Thalassoma duperrey. Mar Biol 72:311-318

> Ruttenberg BI, Haupt AJ, Chiriboga AI, Warner RR (2005) Patterns, causes and consequences of regional variation in the ecology and life history of a reef fish. Oecologia 145:394-403

Spalding MD, Grenfell AM (1997) New estimates of global and regional coral reef areas. Coral Reefs 16:225-230

Srinivasan M, Jones GP (2006) Extended breeding and recruitment periods of fishes on a low latitude coral reef. Coral Reefs 25:673-682

Stearns SC (1992) The evolution of life histories. Oxford University Press, New York

Stobutzki IC, Bellwood DR (1997) Sustained swimming abilities of the late pelagic stages of coral reef fishes. Mar Ecol Prog Ser 149:35-41

> Warner RR, Shapiro DY, Marcanato A, Petersen CW (1995) Sexual conflict: males with highest mating success convey the lowest fertilization benefits to females. Proc R Soc Lond B 262:135-139

Welsford DC, Lyle JM (2005) Estimates of growth and comparisons of growth rates determined from length- and age-based models for populations of purple wrasse (Notolabrus fucicola). Fish Bull 103:697-711

Yamahira K, Conover DO (2002) Intra- vs. interspecific latitudinal variation in growth: adaptation to temperature or seasonality? Ecology 83:1252-1262 
Appendix 1. Subsampling procedures

To guard against comparisons being compromised by unbalanced sampling designs, 2 subsampling procedures were used to check for the following: (1) the effect of an unequal number of locations sampled in each ocean, and (2) the effect of differing sample sizes across locations sampled in both oceans.

(1) The nested analyses for size and longevity were re-run with a balanced sampling design consisting of the 4 Indian Ocean localities and 4 randomly subsampled Pacific Ocean localities. This procedure was repeated 10 times with a new subsample of Pacific Ocean reefs for each analysis. Type III sum of squares was used for all 10 balanced analyses. Results were consistent with those of the unbalanced analysis: nested ANOVAs based on 10 different combinations of 4 random Pacific Ocean locations resulted in a non-significant difference in size across oceans in $100 \%$ of all combinations tested, a significant difference in size across locations in $100 \%$ of all combinations tested, a significant difference in longevity between oceans in $90 \%$ of combinations tested, and a significant difference in longevity across locations in $80 \%$ of combinations tested.

(2) The mean sample size of individuals for the analysis of between-ocean differences in longevity and body size was 45 for the Indian and 131 for the Pacific Ocean, with a minimum sample size of 35 individuals in the Indian Ocean
(Cocos Keeling sample). As the oldest ages occurred in the locations with the highest sample sizes, greater mean age could possibly be the product of a greater sample size. To examine this, populations were subsampled randomly to a new sample size of 35 individuals to match the lowest sample size of the Indian Ocean populations. Nested ANOVAs were re-run based on the new sample sizes, as performed in the original nested analyses. Type V sum of squares was used to account for an unbalanced sampling design (all locations were included except Lizard Island inner reefs and Cocos Keeling lagoon). The results were consistent with those found in the original nested analysis. Nested ANOVAs comparing longevity and body size between the Indian and the Pacific oceans, based on subsamples of 35 individuals, showed a significant difference in longevity $\left(F_{1,39}=7.8974\right.$, $\mathrm{p}<0.05)$ and no significant difference in body size between the 2 ocean basins $\left(F_{1,52}=4.5634, \mathrm{p}>0.05\right)$.

These results support those found using unbalanced sampling designs, and suggest the presence of real biological effects between the 2 oceans. However, subsampling of the Pacific Ocean populations produced evidence that reducing sample size produced slight declines (by an average of $19 \%$ ) in mean maximum age, indicating that balanced sample sizes should be an important element of comparative demographic studies.

Appendix 2. Locality-specific description of fishing pressures on Ctenochaetus striatus across sampled sites

Attempts to develop proxies for fishing pressure such as population per unit length of coastline were unsuccessful due to differences in fishing practices and culture over the broad geographical gradients samples in the present study. Ctenochaetus striatus is harvested primarily by divers through spearing and drive nets. Oman supports 1531 persons per $\mathrm{km}$ of coastline while American Samoa 497 per km. However, fishing pressure is much greater in American Samoa, as diving and spearing are traditional fishing practices in Polynesian but not Arab society.

American Samoa: Overexploited to collapsed reef fishery (Newton et al. 2007). Two acanthurids, Ctenochaetus striatus and Acanthurus lineatus, are targeted in an established spear fishery (Craig et al. 2008). Fishing allocation: Heavy.

Moorea: Underexploited (Newton et al. 2007). C. striatus at Moorea is regarded as ciguatoxic (M. Kulbicki pers. comm.). This and other smaller acanthurids are lightly exploited. Fishing allocation: Light.
Papua New Guinea, Kavieng, Kimbe Bay: Underexploited (Newton et al. 2007). C. striatus supports a light to negligible fishery (Kaly \& Opnai 2005). Both landing and market surveys indicated very low catch rates for small (150-200 mm FL) acanthurids. Fishing allocation: Light.

Oman: No organised reef fishery (www.fao.org/fi/fcp/fcp. asp 2006). C. striatus was recorded only from the offshore Al Halaniyatt Islands in southern Oman and were never observed in local markets (J. MacIlwain pers. comm.) Fishing allocation: None.

Seychelles - granitic islands (Mahe Plateau); Amirantes carbonate reefs: Fully exploited (Newton et al. 2007). Evidence of some net fishing in the Mahe group; no evidence of fishery impacting C. striatus in the southern Amirantes. No evidence of $C$. striatus in market surveys (E. Grandcourt pers. comm..) Fishing allocation: Light.

Cocos Keeling and Great Barrier Reef: No fisheries for this species. Fishing allocation: None.
Editorial responsibility: Hans Heinrich Janssen, Oldendorf/Luhe, Germany
Submitted: August 4, 2006; Accepted: September 25, 2008 Proofs received from author(s): December 15, 2008 